\title{
Oxygen Modulates the Response of First-Trimester Trophoblasts to Hyperglycemia
}

\author{
Julia D. Fröhlich, ${ }^{* \dagger}$ Berthold Huppertz, ${ }^{*}$ \\ Peter M. Abuja, ${ }^{\ddagger}$ Julia König, ${ }^{*}$ and \\ Gernot Desoye ${ }^{\dagger}$ \\ From the Institute of Cell Biology, Histology and Embryology, \\ the Clinic of Obstetrics and Gynecology, ${ }^{\dagger}$ and the Institute of \\ Pathology, ${ }^{\ddagger}$ Medical University of Graz, Graz, Austria
}

Pregestational diabetes retards early embryonic growth. Placental and fetal growth are closely associated, suggesting that placental growth is also impaired. During the first trimester of gestation, oxygen tension rises steeply, leading to excessive production of reactive oxygen species (ROS), which is exacerbated in diabetes and may affect placental development. We hypothesized that oxygen modifies hyperglycemic effects on ROS formation, resulting in decreased first-trimester trophoblast growth. This was tested using a first trimester trophoblast-derived cell line (ACH-3P). Normoglycemia did not alter ACH-3P proliferation at $2.5 \%, 8 \%$, and $21 \%$ oxygen. Hyperglycemic conditions for up to 3 days reduced cell number by $65 \%$ and resulted in cell cycle ( $G_{1}$ - and $S$-phase) changes but only at $21 \%$ oxygen. Proliferation reduction could be partially restored by an inhibitor of mitogen-activated protein kinase (MAPK) ERK1/2 but not of Akt/PkB. Intracellular ROS elevation under hyperglycemia was oxygen independent, whereas mitochondrial superoxide levels were enhanced under hyperglycemia only at $21 \%$ oxygen. Intervention to modulate cytosolic and mitochondrial ROS, using ROS formation inducers and inhibitors, did not alter cell growth under hyperglycemia at $21 \%$ oxygen. The combination of hyperglycemia and high oxygen levels $(21 \%)$ reduces proliferation of human firsttrimester trophoblasts in a ROS-independent manner involving MAPK. This may account for reduced placental growth and, therefore, also for embryonic growth during the first-trimester pregestational diabetic pregnancies when the oxygen tension increases. (Am J Pathol 2012, 180:153-164; DOI: 10.1016/j.ajpath.2011.09.012)

The human placenta is the key organ for sustaining fetal growth and development. It transports maternal nutrients and oxygen to the fetus and synthesizes a variety of hormones. Pathological pregnancies, such as those complicated by early pregnancy failure, ${ }^{1}$ preeclampsia, ${ }^{2}$ and intrauterine growth restriction, ${ }^{3}$ are associated with inadequate placental development.

In pregnancies of diabetic women, the incidence of these pathologies is increased. ${ }^{4-6}$ Maternal diabetes is often associated with high plasma glucose levels, which in turn lead to fetal hyperglycemia. ${ }^{7}$ During the first trimester of a diabetic pregnancy, embryonic growth may be transiently reduced, a condition known as early embryonic growth delay. ${ }^{8,9}$ The strong association between fetal and placental weight ${ }^{10,11}$ makes it tempting to speculate that early embryonic growth delay in diabetes is associated with impaired placental development. Lower maternal serum levels of the human trophoblast-specific hormones placental lactogen and pregnancy-associated plasma protein A support this notion. ${ }^{12}$ Trophoblast proliferation is the key driver of placental growth in early pregnancy. However, little is known about potential changes of placental development in first trimester diabetic pregnancies and the underlying molecular mechanisms.

Early in pregnancy, the placenta and embryo develop in a state of low oxygen tension, and nutrients are supplied by maternal plasma and by secretion of maternal endometrial glands. The placental oxygen tension steeply rises between 8 to 12 weeks of gestation, reflecting the onset of maternal blood flow. Concomitantly, establishment of placental blood flow is associated with a burst of oxidative stress in this organ. Increasing oxygen concentrations lead to generation of reactive oxygen species (ROS), thus exposing the placenta to oxidative stress even in normal pregnancies. ${ }^{13-15}$ Physiological ROS levels can promote and control cellular fate, playing a crucial role in placental development through cellular signaling. Under normal conditions, the placental antioxidant defense systems, which have the capacity to induce conversion of ROS to water and molecular oxygen,

Supported by funding from Medical University of Graz within the PhD program Molecular Medicine (J.D.F. and J.K.). P.M.A. received funding from the Austrian Genome Programme Gen-AU. G.D. was supported by grant 12601 from Jubilee Fund, Austrian National Bank, Vienna.

Accepted for publication September 6, 2011

Address reprint requests to Berthold Huppertz, Ph.D., Institute of Cell Biology, Histology and Embryology, Harrachgasse 21/7, Medical University of Graz, Graz, Austria. E-mail: berthold.huppertz@medunigraz.at. 
prevent ROS overproduction as a consequence of increased metabolic activity of placental mitochondria throughout gestation. ${ }^{16}$

In several tissues, hyperglycemia appears to be directly linked to ROS production. ${ }^{17}$ Thus, high glucose concentrations as found in maternal diabetes can increase oxidative stress and may lead to biochemical disturbances in the complex processes of fetal development and growth. ${ }^{18}$ Several studies have reported that oxidative stress appears to be a key event in diabetic complications. ${ }^{19-21}$ This notion is supported by the findings of decreased vitamin $\mathrm{C}$ and vitamin $\mathrm{E}$ levels and reduced antioxidant capacity of superoxide dismutase (SOD) in diabetic women. ${ }^{22}$

In most mammalian cells, ROS can be generated in the cytosol by xanthine oxidase, nicotinamide adenine dinucleotide phosphate (NADPH) oxidase, cytochrome P450 oxidoreductase, and other NADPH-dependent oxidoreductases, and in mitochondria by the electron transport chain. These mechanisms are also operative in the human placenta. ${ }^{23}$ Cytosolic NADPH oxidase, xanthine oxidase, or cytochrome P450 in the endoplasmic reticulum produces superoxide anion $\left(\mathrm{O}_{2}{ }^{-}\right)$and hydrogen peroxide $\left(\mathrm{H}_{2} \mathrm{O}_{2}\right)$ by transferring electrons from NADPH or NADH, respectively, to molecular oxygen. ${ }^{24,25}$ Mitochondrial ROS is produced as a result of electron transport in the mitochondrial respiratory chain incorrectly coupled to oxidative phosphorylation. Incomplete reduction of oxygen yields $\mathrm{O}_{2}{ }^{-}$, which is eventually converted to $\mathrm{H}_{2} \mathrm{O}_{2}$ and hydroxyl radical. ${ }^{26,27}$ Recent work reported enhanced mitochondrial $\mathrm{O}_{2}{ }^{-}$production under hyperglycemic conditions compared to cells cultured at low glucose levels. ${ }^{28}$

The present study tested the hypothesis that diabetesassociated hyperglycemia in vitro leads to a ROS-induced reduction of placental growth during the first trimester of pregnancy in an oxygen-tension-dependent manner. Because placental growth early in pregnancy is mainly driven by trophoblast growth, we focused on the first-trimester trophoblast. Primary human trophoblasts do not proliferate in culture; therefore, we recently generated a first trimester trophoblast-derived cell line, $\mathrm{ACH}-3 \mathrm{P}$, which closely resembles the primary trophoblasts. ${ }^{29}$ Because $\mathrm{ACH}-3 \mathrm{P}$ cells proliferate in vitro, they represent a particularly suitable model for the purpose of the present study.

\section{Materials and Methods}

\section{Cell Culture}

$\mathrm{ACH}-3 \mathrm{P}$ cells were cultured at $37^{\circ} \mathrm{C}, 5 \% \mathrm{CO}_{2}$, and $21 \% \mathrm{O}_{2}$ in $175-\mathrm{cm}^{2}$ flasks (Nunc, Roskilde, Denmark) in Dulbecco's modified Eagle's medium (DMEM) containing low $\mathrm{D}(+)$-glucose, sodium pyruvate, and L-glutamine (Gibco, Invitrogen, Paisley, UK). Medium was supplemented with $10 \%$ fetal calf serum (FCS; Gibco) and 1\% penicillin/streptomycin (PAA Laboratories, Pasching, Austria). Cells were grown in 75$\mathrm{cm}^{2}$ flasks $\left(5 \times 10^{5}\right.$ cells/flask; Nunc), 6-well dishes $\left(5 \times 10^{4}\right.$ cells/well; Iwaki, Tokyo, Japan), or 24-well dishes $\left(1 \times 10^{4}\right.$ cells/well; Corning, Lowell, MA). The day before any treatment, medium was replaced with fresh DMEM low in $\mathrm{D}(+)$-glucose, without FCS, supplemented with $1 \%$ penicillin/streptomycin overnight. On the following day, the cells were treated with DMEM low (normoglycemia; $5.5 \mathrm{mmol} / \mathrm{L}$ ) or high (hyperglycemia; $25 \mathrm{mmol} / \mathrm{L}$ ) in $\mathrm{D}(+)$-glucose, supplemented with $2 \% \mathrm{FCS}$ and $1 \%$ penicillin/streptomycin, for up to 3 days at $37^{\circ} \mathrm{C}, 5 \% \mathrm{CO}_{2}$, and $2.5 \%, 8 \%$, or $21 \%$ oxygen in an XVIVO incubation system Model G300C (BioSpherix, Lacona, NY). For osmotic control, $19.5 \mathrm{mmol} / \mathrm{L}$ $\llcorner(-)$-glucose (Invitrogen, Eugene, OR) was added to DMEM low in $\mathrm{D}(+)$-glucose. Media were replaced every 24 hours in the XVIVO incubation system.

\section{Quantification of Intracellular ROS}

Intracellular ROS generation was measured using nonfluorescent 2,7-dichlorodihydrofluorescein diacetate $\left(\mathrm{H}_{2} \mathrm{DCFDA}\right.$; Invitrogen), which becomes fluorescent through oxidation and remains in the cytosol after enzymatic intracellular hydrolysis. Relative increase in fluorescence intensity was used as indicator for oxidative stress. ACH-3P cells were cultured in 24-well dishes under normoglycemia, hyperglycemia, and osmotic control conditions at $2.5 \%, 8 \%$, and $21 \%$ oxygen for up to 3 days. After treatment, cells were loaded with $10 \mu \mathrm{mol} / \mathrm{L} \mathrm{H}_{2} \mathrm{DCFDA}$ for 15 minutes, and the dye was replaced by PBS (Gibco) subsequently. Fluorescence intensity was determined $(485 \mathrm{~nm} / 520 \mathrm{~nm}$ excitation/ emission) using a FluoSTAR Optima 413 spectrofluorimeter (BMG Labtechnologies, Offenburg, Germany). For normalization to cell numbers after fluorescence measurements, cells were washed once with Hank's balanced salt solution (Gibco) and loaded with $1 \mu \mathrm{mol} / \mathrm{L}$ CellTrace Calcein Violet AM (Invitrogen) for 30 minutes at $37^{\circ} \mathrm{C}$ to determine cell viability. Wells were measured in staining solution (355 $\mathrm{nm} / 460 \mathrm{~nm}$ excitation/emission). Nonfluorescent Calcein Violet AM permeates cell membranes and is enzymatically hydrolyzed to a fluorescent charged form, retained in living cells. We used it as a proxy for the number of viable cells, accounting for proliferation changes at various culture conditions. Subsequently, the signal obtained by intracellular ROS generation was normalized to that of Calcein Violet for each well.

\section{Quantification of Hydrogen Peroxide}

$\mathrm{H}_{2} \mathrm{O}_{2}$ released from ACH-3P cells after 3 days under hyperglycemia at $21 \%$ oxygen was measured using Amplex Red (10-acetyl-3,7-dihydroxyphenoxazine) in combination with horseradish peroxidase. Cells were cultured in 24-well dishes under normo- and hyperglycemic conditions. After incubation, cells were washed once and incubated with Hank's balanced salt solution containing $100 \mu \mathrm{mol} / \mathrm{L}$ Amplex Red and $1 \mathrm{U} / \mathrm{mL}$ horseradish peroxidase (Sigma Aldrich, Steinheim, Germany). The increase in resorufin fluorescence was immediately measured at $544 \mathrm{~nm} / 580 \mathrm{~nm}$ (excitation/emission) for 20 minutes using monochromatization and top excitation. To account for proliferation changes at various culture conditions, resorufin fluorescence readings were normalized to cell numbers using DAPI staining as a proxy for the number of viable cells. To this end, the cells were washed once and subsequently fixed with $4 \%$ formaldehyde for 15 minutes at 
$37^{\circ} \mathrm{C}$, washed again with Hank's balanced salt solution, and then stained with $500 \mu \mathrm{l}$ DAPI (2.5 $\mu \mathrm{g} / \mathrm{mL}$; Invitrogen) for 10 minutes at $37^{\circ} \mathrm{C}$. Cell fluorescence was measured in PBS at $355 \mathrm{~nm} / 460 \mathrm{~nm}$ (excitation/emission). Subsequently, the signal representing released $\mathrm{H}_{2} \mathrm{O}_{2}$ was normalized to that of DAPI staining for each well.

\section{Real-Time RT-PCR}

Total RNA was isolated using TRI Reagent (Applied Biosystems, Foster City, CA) according to the manufacturer's instruction. RNA concentration was determined by a NanoDrop ND-1000 spectrophotometer (Peqlab Biotechnologies, Erlangen, Germany), and RNA quality was assessed by red staining of denaturing agarose (Biozym, Vienna, Austria) gels. RNA was reverse-transcribed using High-Capacity cDNA Reverse Transcription Kit (Applied Biosystems). Briefly, $2 \mu \mathrm{g}$ of RNA from cells cultured under normo- or hyperglycemia were incubated with the kit components, in a total volume of $20 \mu \mathrm{L}$, for 10 minutes at $25^{\circ} \mathrm{C}$, 120 minutes at $37^{\circ} \mathrm{C}$, and 10 seconds at $85^{\circ} \mathrm{C}$ in a Gene Amp PCR System 9700 thermocycler (Applied Biosystems).

Real-time RT-PCR was performed using QuantiFast SYBR Green PCR Kit (Qiagen, Germantown, MD) for glutathione reductase 1 (Hs_GPX1_1_SG, QuantiTec Primer Assay; Qiagen), nuclear factor (erythroid-derived 2)-like 2 (Hs_ NFE2L2_a_SG, QuantiTec Primer Assay), and heme oxygenase 1 (Hs_HMOX1_1_SG, QuantiTec Primer Assay). Ribosomal L30 (Hs_RPL30_1_SG, QuantiTec Primer Assay) served as internal control. Briefly, cDNA templates were diluted 1:10, and $13.2 \mu \mathrm{L}$ of cDNA was mixed with $13.2 \mu \mathrm{L}$ of SYBR Green $(2 \times)$ and $3.3 \mu \mathrm{L}$ of Primer (10×). A LightCycler 480 (Roche, Mannheim, Germany) was used to analyze gene expression levels in triplicate. The appropriate program involves initial denaturation of 5 minutes at $95^{\circ} \mathrm{C}$ and a subsequent two-step cycle at $95^{\circ} \mathrm{C}$ for 10 seconds and at $60^{\circ} \mathrm{C}$ for 30 seconds for 40 cycles. The $\mathrm{Ct}$ values were automatically calculated by the LightCycler 480 software, and relative gene expression was calculated by the standard $\Delta \Delta \mathrm{Ct}$ method using the expression level of RPL30 as reference.

\section{Visualization of Mitochondrial Superoxide}

Mitochondrial superoxide was assayed with MitoSOX Red (Invitrogen) that permeates living cells and targets mitochondria, where it is oxidized by superoxide, yielding red fluorescence. After 3 days under normo- or hyperglycemia, cells were loaded with $5 \mu \mathrm{mol} / \mathrm{L}$ MitSOX Red for 10 minutes at $37^{\circ} \mathrm{C}$. Microscopy fluorescence images were taken (Eclipse TE2000-U; Nikon, Vienna, Austria) at fixed exposure time. Subsequently, cells were incubated with $2.5 \mu \mathrm{mol} / \mathrm{L}$ CellTracker Green CMFDA (Invitrogen) for 20 minutes at $37^{\circ} \mathrm{C}$ to visualize living cells.

\section{Proliferation Assay}

Cell proliferation was determined by automatic counting of viable and dead cells using CASY Model TT (Schärfe System, Reutlingen, Germany). Proliferation of $\mathrm{ACH}-3 \mathrm{P}$ cells was determined after 1 to 3 days of treatment. For CASY measurements, cells were enzymatically detached, and 50 $\mu \mathrm{L}$ of cell suspension were diluted (1:200) in $10 \mathrm{~mL}$ CASYton (Roche), and viable and dead cells were determined.

\section{Cell Cycle Analysis}

Cell cycle was analyzed by flow cytometry at the Flow Cytometry Core Facility at the Center for Medical Research of the Medical University of Graz. After 3 days of treatment, the cells were harvested, centrifuged, resuspended in $500 \mu \mathrm{L}$ PBS and fixed with $5 \mathrm{~mL}$ of ice-cold $70 \%$ ethanol (Merck, Darmstadt, Germany) at $4^{\circ} \mathrm{C}$ for 10 minutes. After fixation, cells were centrifuged and washed twice with $5 \mathrm{~mL}$ PBS. Pellets were resuspended in $250 \mu \mathrm{L}$ of Pl-staining buffer (Beckman Coulter, Brea, $\mathrm{CA}$ ), incubated for 15 minutes at $37^{\circ} \mathrm{C}$, and kept on ice until analysis. Cell cycle distribution was determined by FACSCalibur (BD Bioscience, San Jose, CA). The proportion of cells in each cell cycle phase $\left(G_{1}, S\right.$, and $\left.G_{2} / M\right)$ was determined by Moefit Software (Verity Software House, Topsham, ME).

\section{Exposure of $\mathrm{ACH}-3 \mathrm{P}$ Cells to Varying Antioxidants Such as Ascorbate, Trolox, and $\mathrm{N}$-Acetylcysteine}

For antioxidant studies, culture medium was supplemented with ascorbate (100 $\mu \mathrm{mol} / \mathrm{L})$, Trolox $(100 \mu \mathrm{mol} / \mathrm{L})$, and $\mathrm{N}$ acetylcysteine (NAC) (1 mmol/L; Sigma-Aldrich). Stock solutions of ascorbate and NAC were prepared in bidistilled water; Trolox was prepared in ethanol. As vehicle control, ethanol was added to the medium and incubated under the same conditions for 3 day.

\section{Exposure of $\mathrm{ACH}-3 \mathrm{P}$ Cells to Allopurinol, Apocynin, VAS-2870, and BCNU}

For inhibition of xanthine and NAPDH oxidases, culture medium was supplemented with varying concentrations of inhibitors; 0.1 to $1 \mathrm{mmol} / \mathrm{L}$ allopurinol, $100 \mu \mathrm{mol} / \mathrm{L}$ and 250 $\mu \mathrm{mol} / \mathrm{L}$ apocynin (Sigma-Aldrich), and $1 \mu \mathrm{mol} / \mathrm{L}$ VAS-2870 (Enzo Life Science, Plymouth Meeting, PA) were used. Stock solution of allopurinol was prepared in bidistilled water. Apocynin was diluted in ethanol, and VAS-2870 stock was prepared in DMSO (Merck). BCNU [1,3-bis-(2-chloroethyl)1-nitrosourea; Sigma-Aldrich] inactivates glutathione reductase and interrupts recycling of glutathione disulfide to glutathione. It was dissolved in PBS and added at final concentrations of $5 \mu \mathrm{mol} / \mathrm{L}, 10 \mu \mathrm{mol} / \mathrm{L}$, and $15 \mu \mathrm{mol} / \mathrm{L}$. As vehicle, ethanol or DMSO was added to medium and incubated under the same conditions for 3 day.

\section{Exposure of $\mathrm{ACH}-3 \mathrm{P}$ Cells to Antimycin A, Oligomycin, and FCCP}

Antimycin $A$ is an inhibitor of complex III of the mitochondrial electron transport chain. Oligomycin was used as ATPase (complex V) inhibitor and FCCP [carbonyl cyanide 4-(trifluoromethoxy) phenylhydrazone; Sigma Al- 
drich] as an uncoupler of oxidative phosphorylation, inhibiting mitochondrial $\mathrm{O}_{2}{ }^{-}$production. Antimycin $\mathrm{A}$ and oligomycin were added at a final concentration of 10 $\mu \mathrm{mol} / \mathrm{L}$ to the medium. FCCP was used at concentrations of $0.1 \mu \mathrm{mol} / \mathrm{L}, 0.3 \mu \mathrm{mol} / \mathrm{L}$, and $0.5 \mu \mathrm{mol} / \mathrm{L}$. Stocks were prepared in ethanol and DMSO, which were also used as vehicle controls. Cells were treated for 3 days.

\section{Exposure of $\mathrm{ACH}-3 \mathrm{P}$ Cells to U0126 and Wortmannin}

U0162 (Calbiochem, San Diego, CA) is a potent and specific inhibitor of MEK1 and MEK2; hence, it blocks the extracellular signal-regulated kinases 1 and 2 (ERK1/2) signaling pathway. Wortmannin (Calbiochem) was used as protein kinase B (Akt/PkB) inhibitor. U0126 and wortmannin were added to the medium at a final concentration of $10 \mu \mathrm{mol} / \mathrm{L}$ and $100 \mathrm{nmol} / \mathrm{L}$, respectively. Stocks were prepared in DMSO, which was also used as vehicle control. Cells were treated for 3 days.

\section{Statistical Analysis}

Statistical analysis used Prism 5 (GraphPad Software, La Jolla, CA). Differences between two treatment conditions were tested with unpaired $t$-test. Differences between three or more groups were analyzed with one-way analysis of variance followed by Bonferroni test. Data were expressed as mean $\pm \mathrm{SD}$. $P$ values of $<0.05$ were considered statistically significant.

\section{Results}

\section{Basal Proliferation under Normoglycemia Is Oxygen-Independent}

We first investigated the effect of varying oxygen concentrations on cell proliferation. To this end, $\mathrm{ACH}-3 \mathrm{P}$ cells were cultured for up to 3 days under normoglycemia at $2.5 \%, 8 \%$, and $21 \%$ oxygen. Subsequently, viable and dead cells were counted. Neither number of viable nor dead ACH-3P cells was significantly altered after 1 to 3 days under normoglycemic conditions at different oxygen concentrations (Figure 1, A and B). The proportion of dead cells after 3 days of incubation amounted to $17 \%$, $19 \%$, and $20 \%$ of total cells at $2.5 \%, 8 \%$, and $21 \%$ oxygen, respectively. These data suggest that basal proliferation of $\mathrm{ACH}-3 \mathrm{P}$ cells under normoglycemia is oxygenindependent.

\section{Proliferation Is Reduced and Cell Cycle Is Altered under Hyperglycemia Only at 21\% Oxygen}

Under hyperglycemic conditions, the number of viable cells did not differ after 1 to 3 days at 2.5\% and $8 \%$ oxygen, compared to normoglycemic conditions. Likewise, the number of dead cells also was not affected by these conditions (Figure 2, A and C). The absence of changes in cell number corresponded to cell cycle anal-
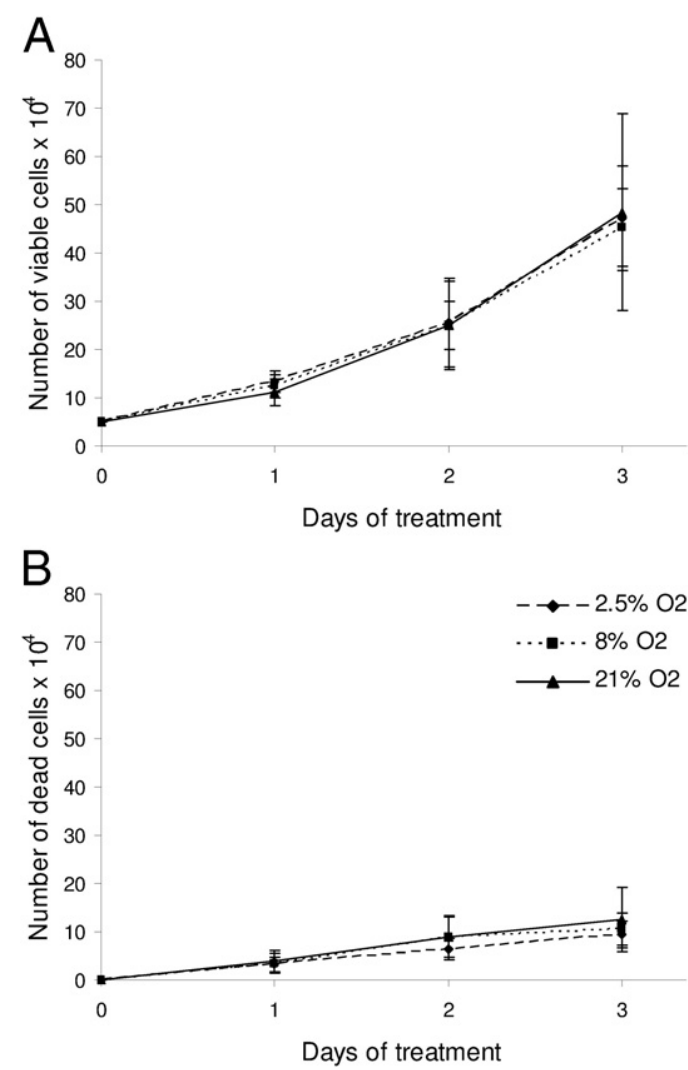

Figure 1. Proliferation of ACH-3P cells for up to 3 days under normoglycemia at $2.5 \%, 8 \%$, and $21 \%$ oxygen. Number of viable cells at $2.5 \%, 8 \%$, and $21 \%$ oxygen (A); number of dead cells at $2.5 \%, 8 \%$, and $21 \%$ oxygen (B); mean $\pm \mathrm{SD}$ $(n=6)$ of three independent experiments

ysis, which did not show significant alterations in the $G_{1^{-}}$, $\mathrm{S}$-, and $\mathrm{G}_{2} / \mathrm{M}$-phase (Figure 2, B and D). Hence, hyperglycemia did not affect cell growth and cell cycle at 2.5\% and $8 \%$ oxygen.

However, at $21 \%$ oxygen, hyperglycemia led to decreased cell proliferation compared to normoglycemia and osmotic control. Two days under hyperglycemic conditions resulted in $40 \%$ fewer viable $\mathrm{ACH}-3 \mathrm{P}$ cells. The number of viable cells was even more decreased (up to $65 \%)$ after 3 days under hyperglycemia $(P<0.001)$ compared to cells cultured under normoglycemic and osmotic control conditions. No alterations in dead cell count were observed (Figure 2E). Cell cycle analysis showed a significant increase in cells in S-phase and a tendency of decreased $\mathrm{G}_{1}$-phase $(P=0.07)$ under hyperglycemia at $21 \%$ oxygen. Compared to cells treated under normoglycemia, the $\mathrm{G}_{2} / \mathrm{M}$-phase was unchanged (Figure $2 \mathrm{~F}$ ). These results indicate that reduced proliferation under hyperglycemia is caused by changes in $\mathrm{G}_{1}$ - and $\mathrm{S}$-, but not in the $\mathrm{G}_{2} / \mathrm{M}$-phase.

\section{Intracellular ROS Generation Is Oxygen- Independent under Hyperglycemia}

Hyperglycemia can directly cause excessive production of ROS. ${ }^{16,30}$ Thus, to determine whether hyperglycemia-induced proliferation changes at $21 \%$, but not at 


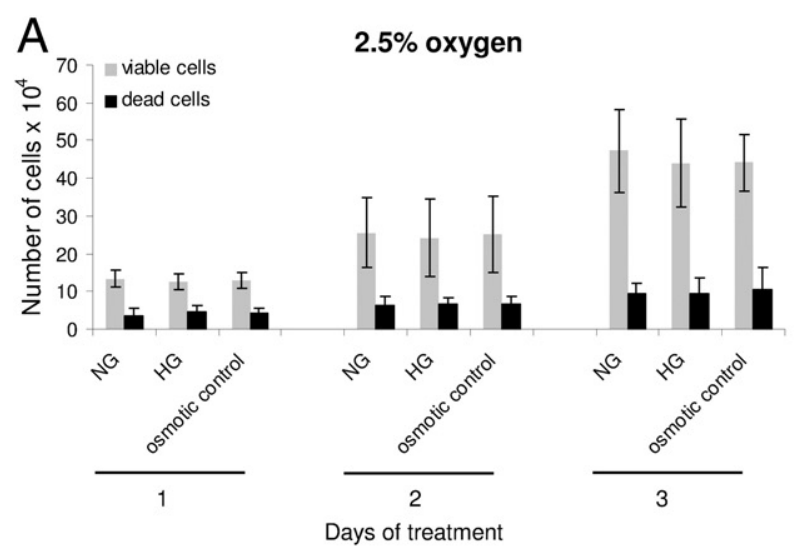

B

\section{$2.5 \%$ oxygen}

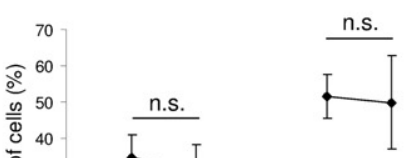

C

$8 \%$ oxygen

D
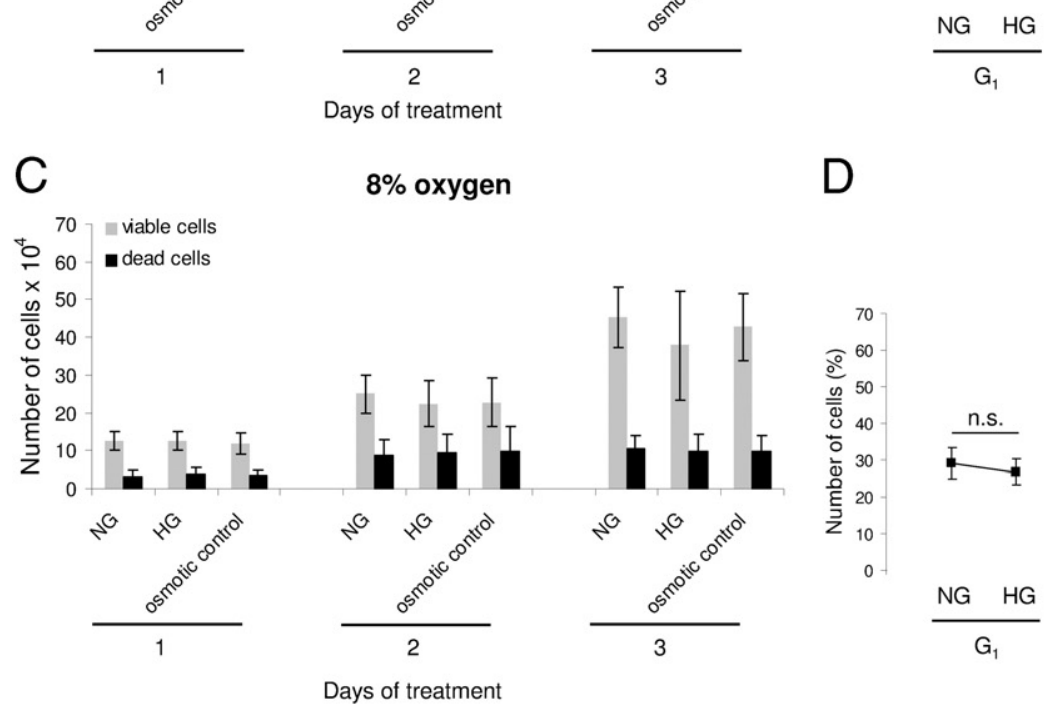

$\frac{N G \quad H G}{S}$

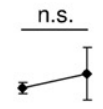

$8 \%$ oxygen

E

$21 \%$ oxygen

$\mathrm{F}$
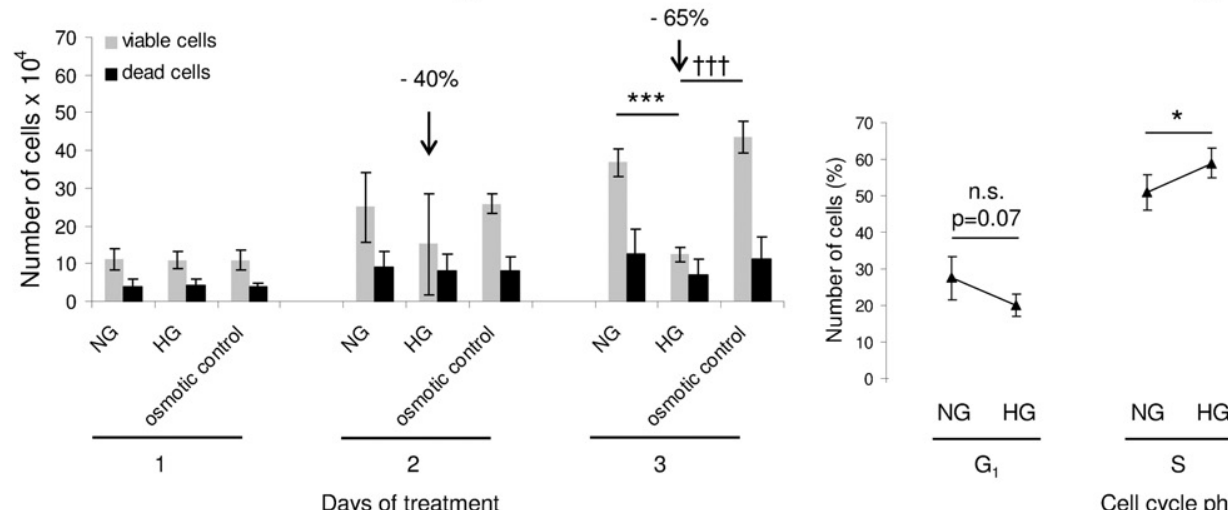<smiles>[3H][Te][3H]</smiles>
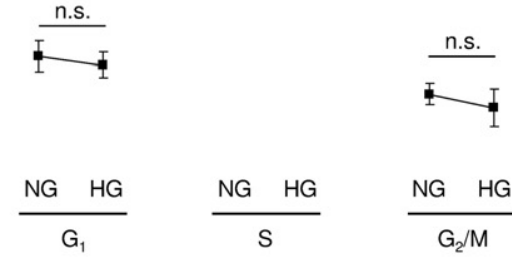

$\frac{N G \quad H G}{S}$

$\frac{N G \quad H G}{G_{2} / M}$

Cell cycle phase

$21 \%$ oxygen

Figure 2. Proliferation and cell cycle analysis of ACH-3P cells cultured for up to 3 days under normoglycemia (NG) and hyperglycemia (HG) at $2.5 \%, 8 \%$, and $21 \%$ oxygen. A, C, and $\mathbf{E}$ : Number of viable (gray bars) and dead (black bars) cells; mean $\pm \mathrm{SD}(n=18) ;(\mathbf{B}, \mathbf{D}$, and $\mathbf{F})$ cell cycle analysis $\left(\mathrm{G}_{1^{-}}, \mathrm{S}-\right.$, and $\mathrm{G}_{2} / \mathrm{M}_{-}$-phase $)$; mean $\pm \mathrm{SD}(n=6)$ from three $(\mathbf{A}, \mathbf{C}$, and $\mathbf{E})$ and four $(\mathbf{B}, \mathbf{D}$, and $\mathbf{F})$ independent experiments, respectively. ${ }^{*} P<0.05,{ }^{* * * *} P<0.001$ versus NG; and ${ }^{t+t} P<0.001$ versus osmotic control. n.s., not significant. Based on 18 replicates, the coefficient of variation for 1 day, 2 days, and 3 days under NG was $17 \%$, $35 \%$, and $23 \%$ at $2.5 \%$ oxygen; $19 \%, 20 \%$, and $18 \%$ at $8 \%$ oxygen; and $25 \%, 37 \%$, and $10 \%$ at $21 \%$ oxygen, respectively. After 1 day, 2 days, and 3 days under HG, the coefficient of variation was $16 \%, 43 \%$, and $27 \%$ at $2.5 \%$ oxygen; $20 \%, 27 \%$, and $38 \%$ at $8 \%$ oxygen; and $21 \%, 88 \%$, and $14 \%$ at $21 \%$ oxygen, respectively.

$2.5 \%$ and $8 \%$ oxygen, are paralleled by changes in oxidative stress, intracellular and mitochondrial ROS levels were measured. HepG2 cells served as a positive control ${ }^{30}$ for increased ROS production under hyperglycemia. Intracellular ROS levels measured by $\mathrm{H}_{2}$ DCFDA were significantly $(P<0.001)$ elevated (1.9fold) after 48 hours at high glucose concentrations compared to cells cultured at normal glucose levels (data not shown).
Under hyperglycemia, 2.1- and 2.2-fold more ROS were produced at $2.5 \%(P<0.001)$ and $8 \%$ oxygen $(P<$ 0.01 versus normoglycemia; 0.05 versus osmotic control), respectively, compared to controls. Interestingly, at $21 \%$ oxygen, $\mathrm{ACH}-3 \mathrm{P}$ cells generated $35 \%$ less $\mathrm{ROS}$ under hyperglycemia $(P<0.001)$. Under normoglycemia, the highest ROS generation was measured at $21 \%$ oxygen $(P<0.001)$. ROS production under hyperglycemia at $21 \%$ oxygen was not significantly different from 

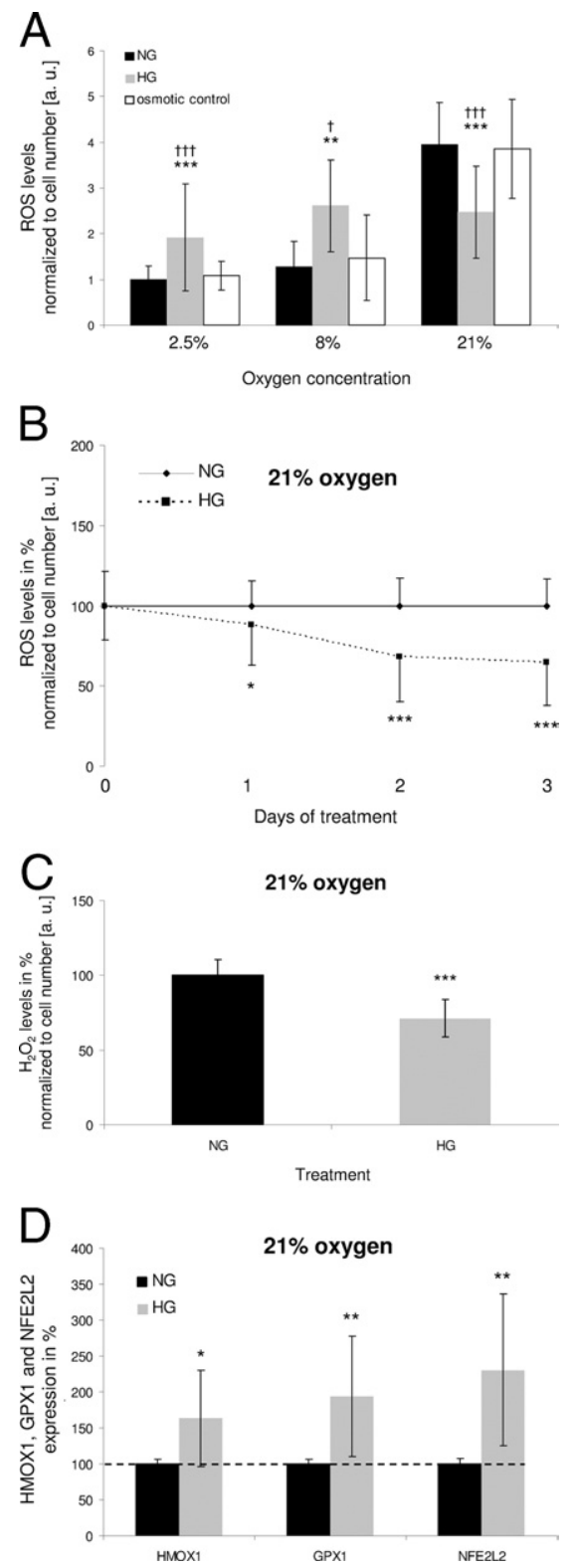

Figure 3. Intracellular ROS levels of $\mathrm{ACH}-3 \mathrm{P}$ cells under hyperglycemia (HG) at $2.5 \%, 8 \%$, and $21 \%$ oxygen and expression levels of stress response genes at $21 \%$ oxygen. A: ACH-3P cells were cultured for 3 days under normoglycemia (NG; black bars), hyperglycemia (gray bars), and osmotic control conditions (white bars) at different oxygen concentrations; (B) ROS levels of ACH-3P cells after $0,1,2$, and 3 days under hyperglycemia at $21 \%$ oxygen. ROS levels were normalized to cell number and are presented as arbitrary units (a. u.); the ROS levels under normoglycemia (control) were set to $100 \%$; $(n=9)$. C: $\mathrm{H}_{2} \mathrm{O}_{2}$ release by $\mathrm{ACH}-3 \mathrm{P}$ cells after 3 days under hyperglycemic conditions. $\mathrm{H}_{2} \mathrm{O}_{2}$ levels were normalized to cell number and are presented as arbitrary units $(n=12)$. D: mRNA expression of HMOX1, GPX1, and NFE2L2 after 3 days under hyperglycemia at 21\% oxygen using quantitative real-time RT-PCR. Expression levels were normalized to RPL30 $(n=3)$; data are presented as mean \pm SD of four $(\mathbf{A}$ and $\mathbf{B})$, two $(\mathbf{C})$ and three (D) independent experiments, respectively. ${ }^{*} P<0.05,{ }^{* *} P<0.01$, and ***:* $P<0.001$ versus NG; and ${ }^{\dagger} P=0.05$ and ${ }^{+1 t} P=0.001$ versus osmotic control.

ROS levels under the same conditions at $2.5 \%$ and $8 \%$ oxygen. This suggests that ROS formation under longterm hyperglycemia is independent of oxygen, whereas under normoglycemia, higher oxygen tension (21\%) augments ROS formation (Figure 3A). Already after 1 day under hyperglycemia, ROS levels were decreased $(P<$
0.05 ) by up to $10 \%$ compared to normoglycemic conditions at $21 \%$ oxygen. They decreased even further by up to $30 \%$ (Figure 3B) after 2 days under these conditions. The lowest ROS levels ( $P<0.001$, decreased by 36\%) were reached after 3 days under hyperglycemia at $21 \%$ oxygen (Figure 3, A and B)

To corroborate the changes in intracellular ROS production found by $\mathrm{H}_{2}$ DCFDA, $\mathrm{H}_{2} \mathrm{O}_{2}$ release from $\mathrm{ACH}-3 \mathrm{P}$ cells was monitored using the Amplex Red assay. After 3 days under hyperglycemia at $21 \%$ oxygen, $\mathrm{H}_{2} \mathrm{O}_{2}$ release was reduced by $28 \%(P<0.001)$ (Figure $3 \mathrm{C}$ ). Taken together, these results indicate decreased ROS levels in $\mathrm{ACH}-3 \mathrm{P}$ cells at high glucose and high oxygen concentrations.

\section{Hyperglycemia Up-Regulates Antioxidant Genes}

Expression levels of several antioxidant-response related genes were analyzed with quantitative real-time RT-PCR. Hyperglycemia significantly increased mRNA levels of HMOX1 (1.6-fold), GPX1 (1.9-fold), and NFE2L2 (2.3-fold) compared to normoglycemic conditions at $21 \%$ oxygen (Figure 3D), indicating an up-regulation of these cellular antioxidant systems under hyperglycemia.

\section{Mitochondrial Superoxide Levels Are Enhanced under Hyperglycemia at 21\% Oxygen}

In addition to cytosolic ROS sources, mitochondria produce ROS as a result of incomplete reduction of oxygen during electron transport in the mitochondrial electron transport chain. ${ }^{27}$ Mitochondrial superoxide levels were determined using MitoSOX Red. Under hyperglycemic conditions (Figure 4D), the cells showed elevated levels of superoxide compared to cells under normoglycemia (Figure 4B). Addition of two electron transport chain inhibitors, antimycin A and oligomycin, served as positive controls. Both inhibitors enhanced superoxide levels under normo- (Figure 4, B versus F) and hyperglycemic (Figure 4, D versus $\mathrm{H}$ ) conditions at $21 \%$ oxygen. In contrast to total intracellular ROS levels, which were reduced under hyperglycemic conditions compared to control cells, mitochondrial superoxide levels were increased by hyperglycemia as compared to normoglycemia at $21 \%$ oxygen. This suggests that hyperglycemia differently alters ROS levels in mitochondria and the cytosol under the experimental conditions.

\section{Addition of Antioxidants Does Not Restore Proliferation under Hyperglycemia at 21\% Oxygen}

To investigate the mechanism behind decreased cell proliferation under hyperglycemia at $21 \%$ oxygen, we assessed the effects of antioxidants (ascorbate, Trolox, and NAC) on proliferation. Whereas the glucose effect on cell number was confirmed again, addition of antioxidants to the culture medium had no effect on cell proliferation (Figure 5, A to C). The number of dead cells was also not altered in any treatment conditions (data not 

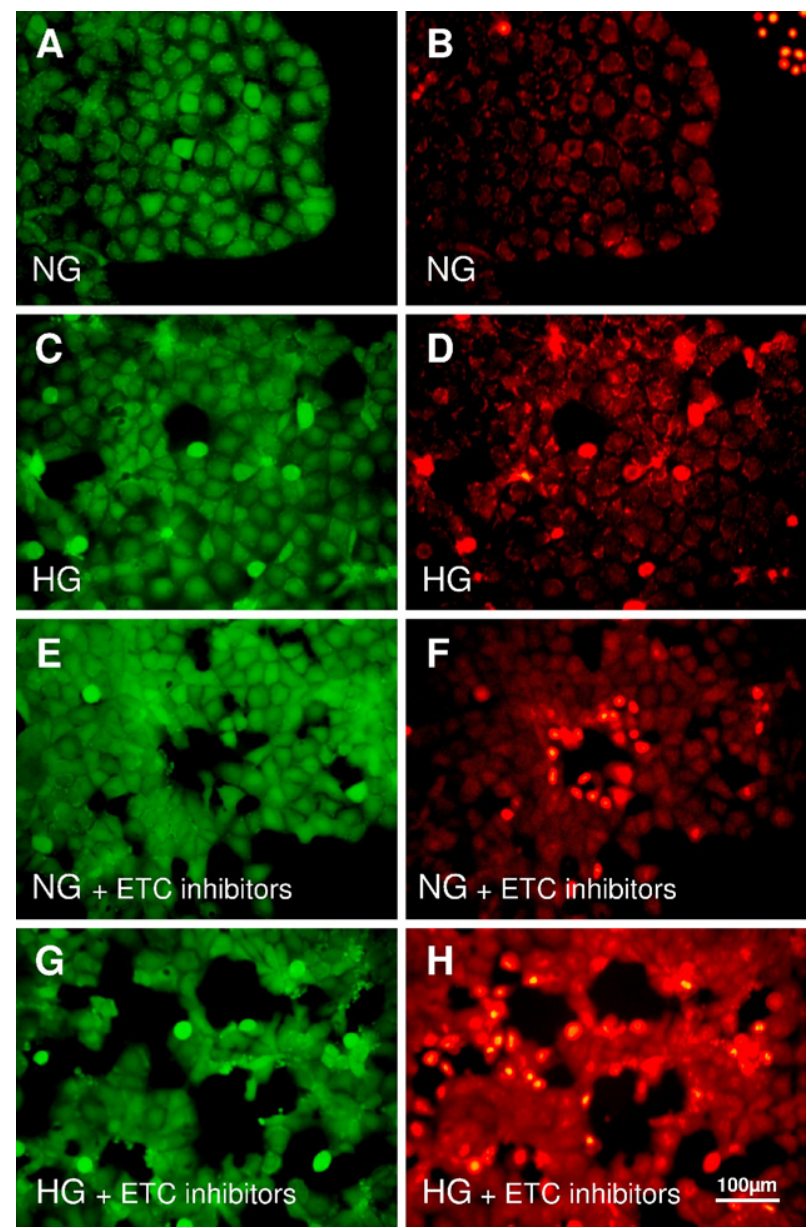

Figure 4. Fluorescence microscopy of mitochondrial superoxide levels after 3 days under hyperglycemia (HG) at $21 \%$ oxygen. After treatment, ACH-3P cells were loaded with CellTracker Green CMFDA (A, C, E, and G) and MitoSOX Red (B, D, F, and $\mathbf{H})$. A and B: Normoglycemia (NG); (C and $\mathbf{D})$ hyperglycemia; (E and $\mathbf{F}$ ) normoglycemia in the presence of two mitochondrial electron transport chain (ETC) inhibitors (antimycin A and oligomycin); $(\mathbf{G}$ and $\mathbf{H})$ hyperglycemia in the presence of antimycin A and oligomycin.

shown). Thus, scavenging ROS by ascorbate, Trolox, and NAC did not restore proliferation of $\mathrm{ACH}-3 \mathrm{P}$ cells under hyperglycemia, suggesting no association between ROS and proliferation under these conditions.

To confirm our hypothesis that proliferation of $\mathrm{ACH}-3 \mathrm{P}$ is ROS independent, we further increased and decreased ROS levels using specific inhibitors. The effects of the reagents used here on cytosolic and mitochondrial ROS formation are shown in Figure 6.

\section{Manipulating Cytosolic ROS Levels Does Not Restore Proliferation under Hyperglycemia at 21\% Oxygen}

Cytosolic ROS levels were manipulated using allopurinol, apocynin, VAS-2870, and BCNU, and measured how this affects cell proliferation. Xanthine and NADPH oxidases are known to generate cytosolic ROS. ${ }^{31,32}$ Inhibition of NADPH oxidase with apocynin (100 $\mu \mathrm{mol} / \mathrm{L}$ and 250 $\mu \mathrm{mol} / \mathrm{L})$ or VAS-2870 (1 $\mu \mathrm{mol} / \mathrm{L})$, a novel NADPH oxidase inhibitor, did not influence the number of viable cells under hyperglycemia (Figure 7, A and B). The inhibition of xanthine oxidase using allopurinol under hyperglycemic conditions also did not increase cell proliferation to normoglycemic levels (Figure 7C). The number of dead cells was not altered under the conditions used here (data not shown). Hence, decreasing cytosolic ROS generation did not restore proliferation of $\mathrm{ACH}-3 \mathrm{P}$ cells, indicating that impaired proliferation under hyperglycemia does not depend on ROS formation.

Further experiments were performed using an inhibitor of glutathione reductase (BCNU), which eventually leads to enhanced ROS generation. Addition of BCNU significantly reduced proliferation under normo- and hyperglycemic conditions in a dose-dependent manner (Figure 7D). The number of dead cells was not altered under any of the conditions (data not shown). In the absence and presence of $5 \mu \mathrm{mol} / \mathrm{L}$ and $10 \mu \mathrm{mol} / \mathrm{L}$ BCNU, proliferation was still significantly decreased under hyperglycemia compared to control cells. Thus, BCNU treatment did not restore the hyperglycemic levels to those of normoglycemia. Collectively, decreasing and increasing cytosolic $\mathrm{ROS}$ generation did not restore proliferation of $\mathrm{ACH}-3 \mathrm{P}$ cells under hyperglycemia at $21 \%$ oxygen.
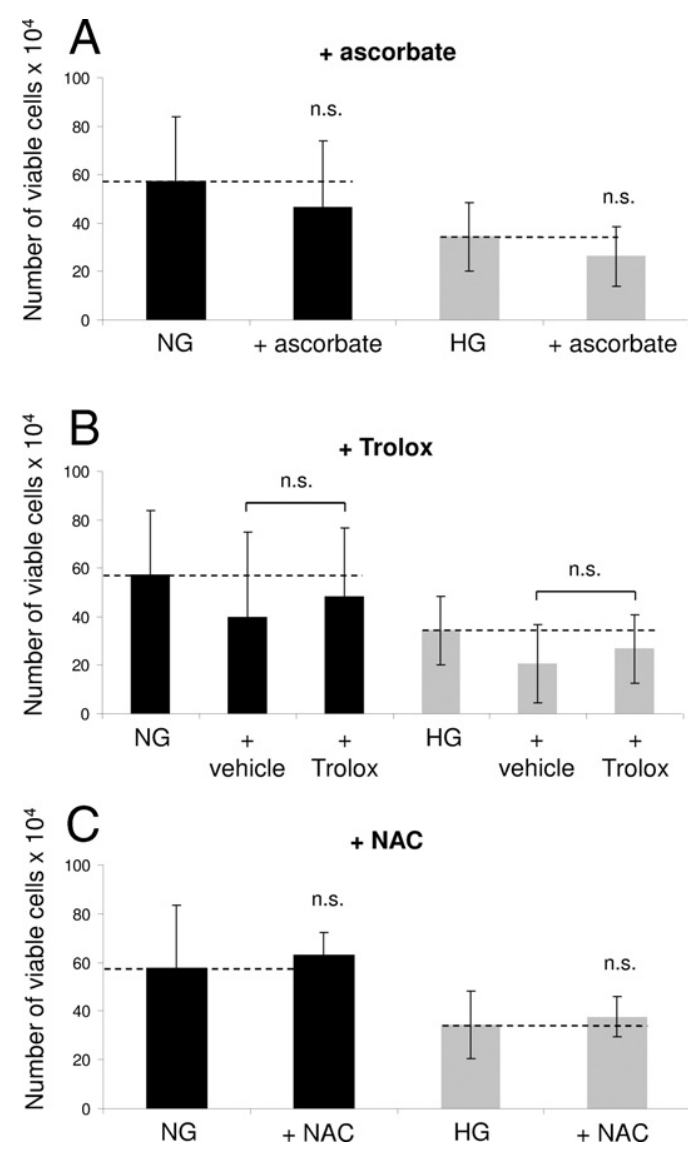

Figure 5. Addition of antioxidants had no effect on cell proliferation under hyperglycemia (HG) at $21 \%$ oxygen. ACH-3P cells were cultured for 3 days under normoglycemia (NG; black bars) and hyperglycemia (gray bars) in the presence and absence of antioxidants at $21 \%$ oxygen. A: Ascorbate (100 $\mu \mathrm{mol} / \mathrm{L})$, (B) Trolox $(100 \mu \mathrm{mol} / \mathrm{L})$, and $(\mathbf{C})$ NAC $(1 \mu \mathrm{mol} / \mathrm{L})$; number of viable cells are presented as mean $\pm \mathrm{SD}(n=6)$ of three independent experiments. n.s., not significant. Based on 18 replicates, the coefficient of variation under NG and $\mathrm{HG}$ was $45 \%$ and $40 \%$, respectively. 


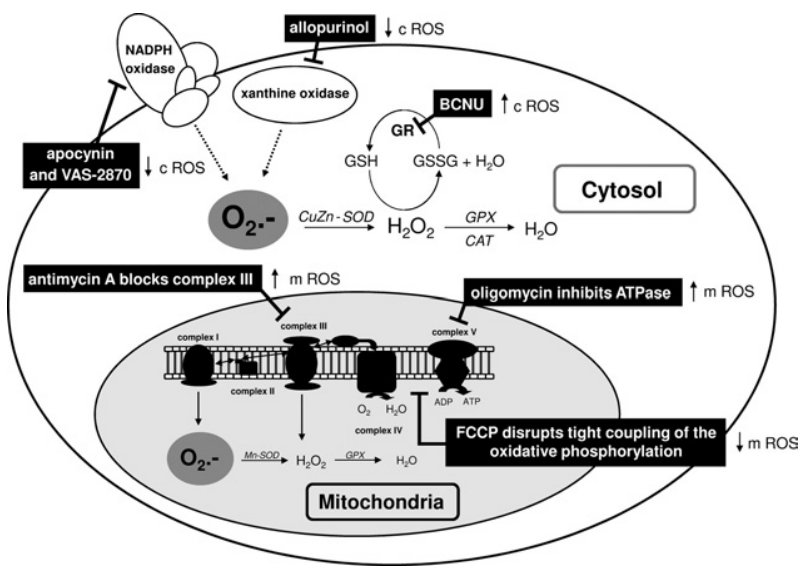

Figure 6. Effect of inhibitors on increasing and decreasing cytosolic (c) and mitochondrial (m) ROS generation. Allopurinol blocks xanthine oxidase and, therefore, reduces cytosolic ROS generation. Apocynin and VAS-2870 are inhibitors for membrane-bound NADPH oxidase and lead to decreased ROS formation in the cytosol. BCNU inhibits glutathione reductase (GR) and thereby prevents recycling of the oxidized glutathione disulfide (GSSG) to the reduced form of glutathione (GSH), which may cause increased intracellular ROS production. FCCP disrupts the tight coupling of the oxidative phosphorylation and reduces mitochondrial superoxide anion $\left(\mathrm{O}_{2}{ }^{-}\right)$generation; antimycin A blocks complex III; and oligomycin inhibits ATPase (complex $\mathrm{V})$ in the mitochondrial electron transport chain, leading to enhanced superoxide levels. CAT, catalase; CuZn-SOD, copper-zinc superoxide dismutase; GPX, glutathione peroxidase; Mn-SOD, manganese superoxide dismutase.

\section{Enhanced and Reduced Mitochondrial Superoxide Levels Do Not Restore Proliferation under Hyperglycemia at 21\% Oxygen}

Hyperglycemia had a different effect on cellular and mitochondrial ROS levels. Therefore, we investigated the effect of mitochondrial ROS on cell proliferation by manipulating mitochondrial superoxide levels. Cells were treated with FCCP, antimycin A, and oligomycin to reduce (FCCP) or elevate (antimycin A, oligomycin) superoxide levels under hyperglycemia at $21 \%$ oxygen. Varying concentrations of FCCP could not restore proliferation (Figure 8A). After the addition of 0.5 $\mu \mathrm{mol} / \mathrm{L}$ FCCP, significantly fewer viable cells were observed under normo- and hyperglycemic conditions. Lower FCCP concentrations reduced the number of viable cells under hyperglycemia (Figure 8A). The number of dead cells did not change under any of the conditions (data not shown). Hence, decreased superoxide levels via mitochondria could not improve proliferation under hyperglycemia at $21 \%$ oxygen.

Forced elevation of superoxide levels with antimycin $\mathrm{A}^{33}$ (Figure 8B) decreased the number of viable cells under normo- $(P<0.001)$ and hyperglycemia compared to vehicle controls, whereas the number of dead cells was not changed (data not shown). Oligomycin had a similar effect on proliferation (Figure 8C).

Cell growth under hyperglycemia was still reduced after the addition of antimycin A and oligomycin compared to cells treated under normoglycemic conditions. These results suggest that mitochondrial ROS formation does not restore cell proliferation under hyperglycemia at $21 \%$ oxygen.
Inhibition of the ERK 1/2, but Not the Akt/PkB, Signaling Pathway Increase Cell Proliferation under Hyperglycemia at 21\% Oxygen

The number of viable cells was increased $(P<0.001)$ in the presence of ERK1/2 inhibitor U0126 (10 $\mu \mathrm{mol} / \mathrm{L})$ un-
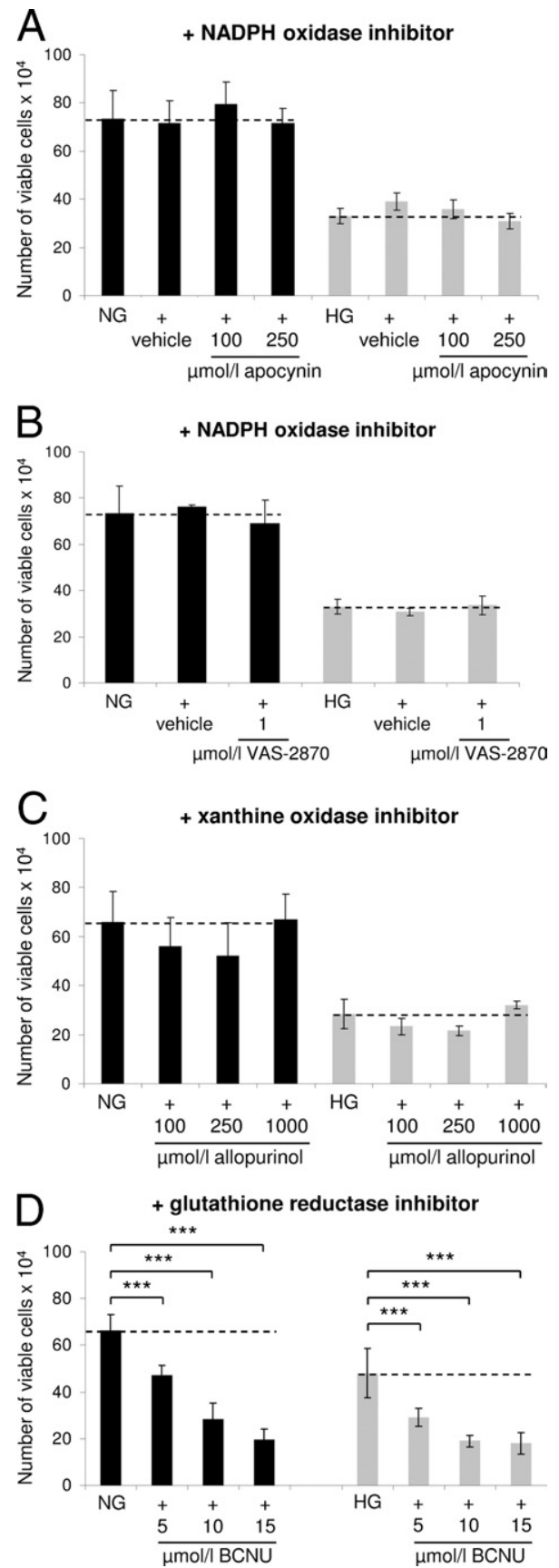

Figure 7. Increased and decreased cytosolic ROS generation did not alter $\mathrm{ACH}-3 \mathrm{P}$ proliferation under hyperglycemia (HG) at $21 \%$ oxygen. $\mathrm{ACH}-3 \mathrm{P}$ cells were treated for 3 days under normoglycemia (NG; black bars) and hyperglycemia (gray bars) in the presence and absence of NADPH oxidase (apocynin and VAS-2870), xanthine oxidase (allopurinol), and glutathione reductase inhibitors (BCNU) at 21\% oxygen. A: Apocynin, (B) VAS-2870, (C) allopurinol, (D) BCNU. Number of viable cells are presented as mean \pm SD $(n=6) .{ }^{* * * *} P<0.001$ versus NG or HG and NG + vehicle or $\mathrm{HG}+$ vehicle. Based on six replicates, the coefficient of variation under NG and HG was (A and B) $16 \%$ and $10 \%$, (C) $19 \%$ and $21 \%$, (D) $10 \%$ and $22 \%$, respectively. 

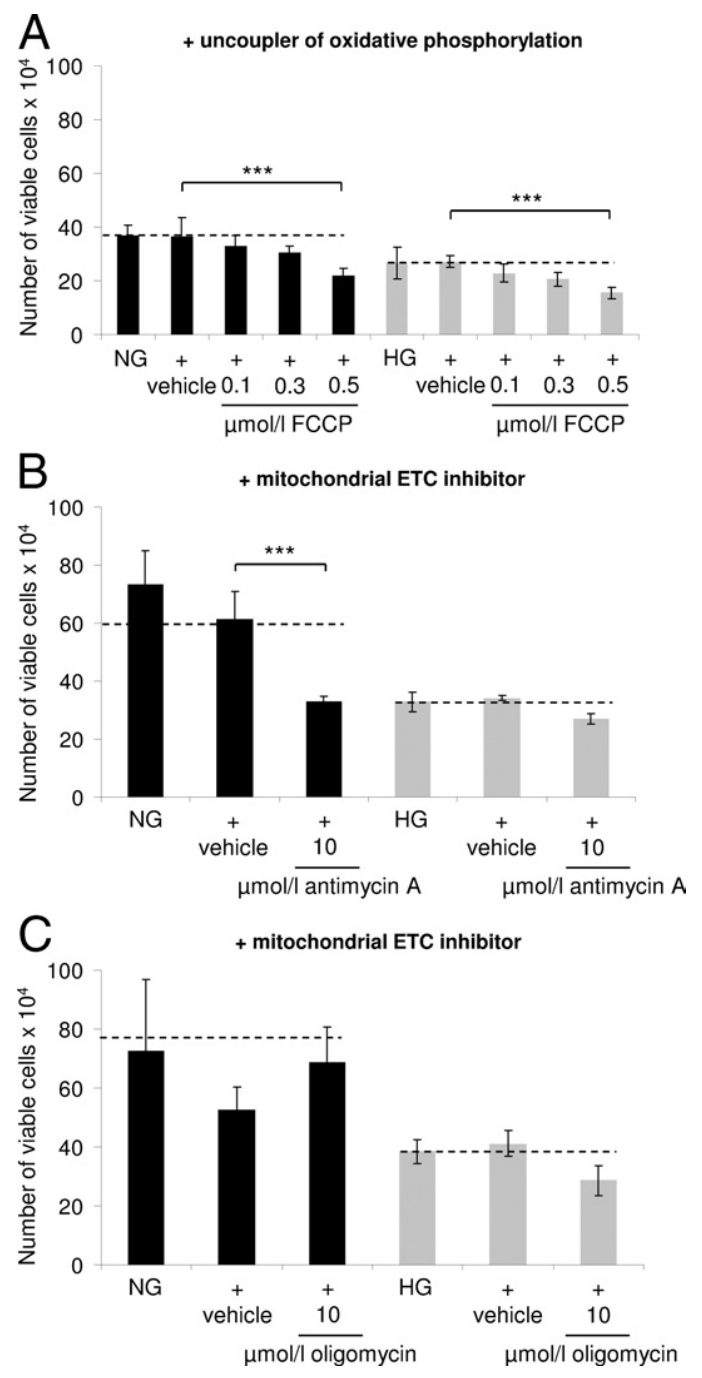

Figure 8. Reduced or enhanced mitochondrial superoxide levels did not restore $\mathrm{ACH}-3 \mathrm{P}$ proliferation under hyperglycemia (HG) at $21 \%$ oxygen $\mathrm{ACH}-3 \mathrm{P}$ cells were treated for 3 days under normoglycemia (NG; black bars) and hyperglycemia (gray bars) in the presence and absence of an uncoupler (FCCP) and two different mitochondrial electron transport chain (ETC) inhibitors (antimycin A and oligomycin) at 21\% oxygen. Number of viable cells after addition of (A) FCCP, (B) antimycin A, and (C) oligomycin. Number of viable cells are presented as mean $\pm \mathrm{SD}(n=6)$. ${ }^{* * * *} P<0.001$ versus $\mathrm{NG}+$ vehicle or $\mathrm{HG}+$ vehicle. Based on six replicates, the coefficient of variation under NG and HG was (A) $10 \%$ and $22 \%$, (B) $16 \%$ and $10 \%$, and (C) $33 \%$ and $10 \%$, respectively.

der hyperglycemia at $21 \%$ oxygen compared to cells cultured with vehicle under the same conditions, suggesting that inhibition of ERK1/2 partially abolished the high glucose effect. Blocking the Akt/PkB signaling pathway by addition of wortmannin $(100 \mathrm{nmol} / \mathrm{L})$ did not restore hyperglycemia-reduced $\mathrm{ACH}-3 \mathrm{P}$ proliferation under these conditions (Figure 9). The combination of both inhibitors resulted in the same effect as U0126 alone. This indicates that ERK1/2, but not Akt/PkB, is involved in the hyperglycemia-mediated effect. The partial effect of the ERK1/2 inhibitor suggests that other mitogen-activated protein kinases such as ERK5, JNK, and p38, also might be involved. The number of dead cells under hyperglycemic conditions was also affected by ERK1/2 and Akt/ $\mathrm{PkB}$ inhibition. Significantly more dead cells were found using U0126 and wortmannin either singly or in combination compared to cells treated with vehicle control (data not shown).

\section{Discussion}

The effects of maternal diabetes on the placenta at the end of gestation have received much attention. ${ }^{34}$ However, only little information is available on placental development in the first trimester of a diabetic pregnancy. In the present in vitro study, we focused on the trophoblast, the key placental cell type in early pregnancy, and investigated its growth in response to the diabetic environment. We used long-term hyperglycemic conditions in vitro to represent one component of the diabetic environment in vivo. The experiments were performed under varying oxygen conditions $\left(2.5 \%, 8 \%\right.$, and $\left.21 \% \mathrm{O}_{2}\right)$ to mimic the increasing oxygen concentrations in vivo during the first trimester of pregnancy. The characteristics of $\mathrm{ACH}-3 \mathrm{P}$ cells closely resemble many characteristics of different aspects of primary first-trimester trophoblasts but are combined with the potential to proliferate, which the primary trophoblasts do not do in vitro. ${ }^{29}$

To the best of our knowledge, this is the first study in which oxygen was used as a modulator of the hyperglycemic response. The key findings of our study were: i) long-term hyperglycemia reduced $\mathrm{ACH}-3 \mathrm{P}$ cell proliferation at $21 \%$ oxygen, whereas high glucose conditions did not affect cell growth under lower oxygen concentrations; ii) hyperglycemia increased trophoblast ROS levels independently of oxygen; and iii) the hyperglycemic effect on proliferation was independent of ROS levels. In none of the experiments was the number of dead cells altered. Thus, we conclude that hyperglycemia did not influence cell apoptosis and cell survival.

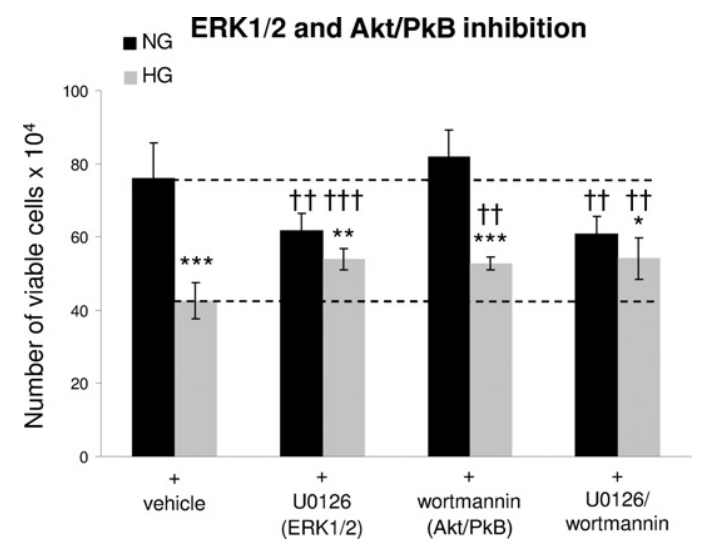

Figure 9. Inhibition of ERK1/2 signaling pathway leads to increased ACH-3P cell proliferation under hyperglycemia (HG) at $21 \%$ oxygen. ACH-3P cells were treated for 3 days under normoglycemia (NG; black bars) and hyperglycemia (gray bars) in the presence and absence (DMSO vehicle) of 10 $\mu \mathrm{mol} / \mathrm{L} \mathrm{U} 0126$ (ERK1/2 inhibitor) or $10 \mathrm{nmol} / \mathrm{L}$ wortmannin (Akt/Pkb inhibitor) at $21 \%$ oxygen. Number of viable cells are presented as mean \pm SD $(n=6) .{ }^{*} P<0.05,{ }^{* *} P<0.01$, and ${ }^{* * * *} P<0.001$ versus NG + vehicle, NG + $\mathrm{U} 0126, \mathrm{NG}+$ wortmanin or NG + U0126/wortmannin, respectively; ${ }^{{ }^{\dagger}} P=0.01,{ }^{\dagger t} P=0.001$ versus $\mathrm{NG}+$ vehicle or $\mathrm{HG}+$ vehicle, respectively. Based on six replicates, the coefficient of variation under $N G+$ vehicle and HG + vehicle was $13 \%$ and $12 \%$, respectively. 


\section{Oxygen-Dependent Proliferation under Hyperglycemia}

At about week 12 of gestation, maternal blood flow toward the placenta is fully established, leading to enhanced oxygen tension within the organ. ${ }^{13}$ The rapid increase of placental oxygen concentrations is associated with increased oxidative stress. ROS production occurs in normal pregnancies, but is even more pronounced in pregnancies complicated with diabetes. ${ }^{35}$

It is tempting to speculate that this could be an explanation for our findings that hyperglycemia-reduced proliferation is oxygen-dependent, whereas basal proliferation is not modified by oxygen concentrations. Previous proliferation studies under hyperglycemic conditions in different cell types and tissues showed inconsistent findings. Decreased proliferation, ${ }^{11,36}$ as well as enhanced cell growth, ${ }^{37,38}$ was observed, indicating that the hyperglycemic effect on proliferation is cell-specific.

Cell cycle analysis showed, at $21 \%$ oxygen, modifications in specific cell cycle phases. Long-term hyperglycemia resulted in reduced $G_{1}$-phase and significantly increased S-phase cell populations, whereas $G_{2} / M$ phase was not affected under these conditions. This may reflect an arrest at some point past S-phase of the cell cycle. Hyperglycemia may affect cyclins and cyclin-dependent kinase inhibitors ${ }^{39}$; however, the specific mechanisms underlying cell cycle changes in our setting are still unknown.

\section{Oxygen-Independent ROS Formation under Hyperglycemia}

In placental explants, an increase of oxidative stress markers after hypoxia-reoxygenation has been reported, ${ }^{40}$ suggesting that ROS formation is oxygen dependent. Furthermore, a large body of evidence shows increased ROS levels caused by hyperglycemia in different cell types. ${ }^{41,42}$ Thus, previous observations indicate that both oxygen and high glucose concentrations can lead to oxidative stress in cells and tissues.

To examine the underlying mechanisms leading to decreased trophoblast proliferation at $21 \%$ oxygen, we determined ROS levels and $\mathrm{H}_{2} \mathrm{O}_{2}$ release in these cells. Intracellular ROS production was enhanced under hyperglycemia at $2.5 \%$ and $8 \%$ oxygen compared to cells cultured under normoglycemic conditions. This set of data indicates that at $2.5 \%$ and $8 \%$ oxygen under hyperglycemia, $\mathrm{ACH}-3 \mathrm{P}$ cells produced significantly more ROS, which did not affect proliferation. At $21 \%$ oxygen, the situation was different: $\mathrm{ACH}-3 \mathrm{P}$ cells showed higher ROS generation and $\mathrm{H}_{2} \mathrm{O}_{2}$ release under normoglycemia. Indeed, ROS levels under hyperglycemia were not significantly altered at $21 \%$ oxygen compared to cells after 3 days under high glucose concentrations at $2.5 \%$ and $8 \%$ oxygen. These findings, independently obtained by two different methods, indicate that ROS production under normoglycemia is oxygen-dependent, but oxygen-independent under hyperglycemia.
In a likely scenario, reduced ROS levels under hyperglycemia at $21 \%$ oxygen can be the consequence of cell adaption to high glucose concentrations by up-regulating cellular antioxidant systems, which may have an impact on proliferation and the cell cycle. Such effects of hyperglycemia on antioxidant systems have been reported previously ${ }^{43,44}$ and were confirmed here. Hyperglycemia up-regulated heme oxygenase 1, glutathione peroxidase 1, and nuclear factor (erythroid-derived 2)-like 2 compared to normoglycemic conditions. All three genes encode proteins with a special function as antioxidants, strongly supporting the notion that $\mathrm{ACH}-3 \mathrm{P}$ cells had adjusted to the diabetic environment (Figure 3D).

In addition, mitochondrial mass in the human placenta increases with gestational age, making possible an increase in superoxide production by mitochondria throughout the course of pregnancy. ${ }^{24}$ It had been shown that first-trimester trophoblast mitochondria are resistant against hyperglycemia-induced high-amplitude swelling. ${ }^{45}$ Recent work highlighted the influence of mitochondrial superoxide on cell proliferation. ${ }^{46}$ As shown in Figure 4D, superoxide levels were increased in cells treated under hyperglycemia and $21 \%$ oxygen. Therefore, we further hypothesized that elevated mitochondrial ROS formation contributes to decreased proliferation.

\section{Cytosolic versus Mitochondrial ROS and Their Influence on Proliferation}

To investigate whether cytosolic and mitochondrial ROS influence proliferation at $21 \%$ oxygen, we modulated ROS generation in both cell compartments (Figure 6). Addition of antioxidants, such as ascorbate, ${ }^{47}$ Trolox, ${ }^{48}$ and $\mathrm{NAC},{ }^{49}$ which are known to generally decrease intracellular ROS levels, had no beneficial impact on proliferation under hyperglycemic conditions.

Proliferation could not be restored by supplementation of any antioxidant. Our findings were in line with previous observations in endothelial progenitor cells where addition of antioxidants (SOD, catalase, ascorbate, NAC) did not alter proliferation under hyperglycemic conditions. ${ }^{50}$ This may represent a cell-specific effect since catalase completely reversed the proliferation effect of high glucose treatment in aortic smooth muscle cells. ${ }^{51}$ Interestingly, decreasing and increasing cytosolic and mitochondrial ROS levels did not modify $\mathrm{ACH}-3 \mathrm{P}$ proliferation under hyperglycemia, suggesting ROS and cell proliferation are not associated in $\mathrm{ACH}-3 \mathrm{P}$ cells under the conditions used here, which further corroborates the lack of effect of the antioxidants applied.

Our results indicate that high glucose levels do not control proliferation by using intracellular ROS as signaling molecules. To gain insight into potential pathways involved, we focused on two key kinases, Akt/PkB and ERK1/2. Akt/PkB inhibition did not restore proliferation under hyperglycemia at $21 \%$ oxygen, indicating that Akt/ $\mathrm{PkB}$ is not involved. However, inhibition of ERK1/2 partially abolished reduced proliferation under hyperglycemia at $21 \%$ oxygen. Thus, signaling through the MAP kinase pathway contributes to the effect of hyperglyce- 
mia, but the involvement of other mechanisms cannot be excluded.

\section{Pathophysiological Implications}

Early in pregnancy, the oxygen tension in the intervillous space and within the placenta is low. At this stage, hyperglycemia may not affect the development and proliferation of the trophoblast, and hence, placental growth. Later in the first trimester, when the oxygen tension rises, the trophoblast becomes sensitive to the hyperglycemic environment and reduces its proliferation. This may result in diminished nutrient delivery to the fetus, ultimately resulting in reduced growth of the fetus proper. ${ }^{8}$ In this scenario, the trophoblast would be the primary target of the diabetic environment, and the fetus would respond with some delay. Some support for this speculation comes from the observation that fetal growth was delayed only at week 12 after menstruation, but not at week 8 after menstruation, although the oxygen tension rises the most between week 8 and 10 after menstruation. ${ }^{9}$

Here, we demonstrate for the first time that a ROSindependent decrease of proliferation under hyperglycemia can be caused by elevated oxygen concentrations. These findings suggest that in diabetes, reduced trophoblast proliferation may have an impact on embryonic growth at the time of oxygen increase at the end of the first trimester of pregnancy. Thus, we propose that maternal diabetes alters placental development during the first trimester of gestation. Whether the increased risk for preeclampsia, miscarriage, and intrauterine growth restriction in diabetic pregnancies ${ }^{4-6}$ is related to the impaired trophoblast growth remains an open question.

\section{Acknowledgments}

We thank Monika Siwetz, Gerit Moser, Martin Gauster, Amin El-Heliebi, and Veronika Berghold (Institute of Cell Biology, Histology and Embryology, Medical University of Graz), and Heidi Miedl, Ursula Hiden, and Luciana Lassance Gomes (Clinic of Obstetrics and Gynecology, Medical University of Graz) for their help and expertise. Thanks to Aniket Nikam (Institute of Pathology, Medical University of Graz) for his essential support in statistical issues.

\section{References}

1. Jauniaux E, Burton GJ: Pathophysiology of histological changes in early pregnancy loss. Placenta 2005, 26:114-123

2. Huppertz B: Placental origins of preeclampsia: challenging the current hypothesis. Hypertension 2008, 51:970-975

3. Burton GJ, Jauniaux E, Charnock-Jones DS: The influence of the intrauterine environment on human placental development. Int J Dev Biol 2010, 54:303-312

4. Sibai BM: Risk factors, pregnancy complications, and prevention of hypertensive disorders in women with pregravid diabetes mellitus. $J$ Matern Fetal Med 2000, 9:62-65

5. Mammon K, Keshet R, Savion S, Pekar O, Zaslavsky Z, Fein A, Toder $\mathrm{V}$, Torchinsky A: Diabetes-induced fetal growth retardation is associated with suppression of NF-kappaB activity in embryos. Rev Diabet Stud 2005, 2:27-34
6. Biggers JD, Summers MC: Impact of hyperglycemia on early embryo development and embryopathy: in vitro experiments using a mouse model. Hum Reprod 2008, 23:2874-2875

7. Freinkel N: Banting Lecture 1980. Of pregnancy and progeny. Diabetes 1980, 29:1023-1035

8. Pedersen JF, Molsted-Pedersen L, Mortensen HB: Fetal growth delay and maternal hemoglobin A1c in early diabetic pregnancy. Obstet Gynecol 1984, 64:351-352

9. Brown ZA, Mills JL, Metzger BE, Knopp RH, Simpson JL, JovanovicPeterson L, Scheer K, Van Allen MI, Aarons JH, Reed GF: Early sonographic evaluation for fetal growth delay and congenital malformations in pregnancies complicated by insulin-requiring diabetes. National Institute of Child Health and Human Development Diabetes in Early Pregnancy Study. Diabetes Care 1992, 15:613-619

10. Thame M, Osmond C, Bennett F, Wilks R, Forrester T: Fetal growth is directly related to maternal anthropometry and placental volume. Eur J Clin Nutr 2004, 58:894-900

11. Weiss U, Cervar M, Puerstner P, Schmut $O$, Haas J, Mauschitz R, Arikan G, Desoye G: Hyperglycaemia in vitro alters the proliferation and mitochondrial activity of the choriocarcinoma cell lines BeWo. JAR and JEG-3 as models for human first-trimester trophoblast Diabetologia 2001, 44:209-219

12. Pedersen JF, Sorensen S, Molsted-Pedersen L: Serum levels of human placental lactogen, pregnancy-associated plasma protein A and endometrial secretory protein PP14 in first trimester of diabetic pregnancy. Acta Obstet Gynecol Scand 1998, 77:155-158

13. Huppertz B, Gauster M, Orendi K, Konig J, Moser G: Oxygen as modulator of trophoblast invasion. J Anat 2009, 215:14-20

14. Jauniaux E, Watson AL, Hempstock J, Bao YP, Skepper JN, Burton GJ: Onset of maternal arterial blood flow and placental oxidative stress. A possible factor in human early pregnancy failure. Am J Pathol 2000, 157:2111-2122

15. Burton GJ: Oxygen, the Janus gas; its effects on human placental development and function. J Anat 2009, 215:27-35

16. Roberts CK, Sindhu KK: Oxidative stress and metabolic syndrome. Life Sci 2009, 84:705-712

17. Choi SW, Benzie IF, Ma SW, Strain JJ, Hannigan BM: Acute hyperglycemia and oxidative stress: direct cause and effect? Free Radic Biol Med 2008, 44:1217-1231

18. Dennery PA: Effects of oxidative stress on embryonic development. Birth Defects Res C Embryo Today 2007, 81:155-162

19. Wentzel P, Ejdesjo A, Eriksson UJ: Maternal diabetes in vivo and high glucose in vitro diminish GAPDH activity in rat embryos. Diabetes 2003, 52:1222-1228

20. Wentzel P, Eriksson UJ: Antioxidants diminish developmental damage induced by high glucose and cyclooxygenase inhibitors in rat embryos in vitro. Diabetes 1998, 47:677-684

21. Qi W, Chen X, Gilbert RE, Zhang Y, Waltham M, Schache M, Kelly DJ, Pollock CA: High glucose-induced thioredoxin-interacting protein in renal proximal tubule cells is independent of transforming growth factor-beta1. Am J Pathol 2007, 171:744-754

22. Peuchant E, Brun JL, Rigalleau V, Dubourg L, Thomas MJ, Daniel JY, Leng JJ, Gin $\mathrm{H}$ : Oxidative and antioxidative status in pregnant women with either gestational or type 1 diabetes. Clin Biochem 2004, 37: 293-298

23. Myatt $L$ : Review: reactive oxygen and nitrogen species and functional adaptation of the placenta. Placenta 2010, 31 (Suppl):S66-S69

24. Myatt L, Cui X: Oxidative stress in the placenta. Histochem Cell Biol 2004, 122:369-382

25. Gao L, Mann GE: Vascular NAD(P)H oxidase activation in diabetes: a double-edged sword in redox signaling. Cardiovasc Res 2009, 82: 9-20

26. Zhang DX, Gutterman DD: Mitochondrial reactive oxygen speciesmediated signaling in endothelial cells. Am J Physiol Heart Circ Physiol 2007, 292:H2023-H2031

27. Murphy MP: How mitochondria produce reactive oxygen species. Biochem J 2009, 417:1-13

28. Makino A, Scott BT, Dillmann WH: Mitochondrial fragmentation and superoxide anion production in coronary endothelial cells from a mouse model of type 1 diabetes. Diabetologia 2010, 53:1783-1794

29. Hiden U, Wadsack C, Prutsch N, Gauster M, Weiss U, Frank HG Schmitz U, Fast-Hirsch C, Hengstschlager M, Potgens A, Ruben A, Knofler M, Haslinger P, Huppertz B, Bilban M, Kaufmann P, Desoye $\mathrm{G}$ : The first trimester human trophoblast cell line $\mathrm{ACH}-3 \mathrm{P}$ : a novel tool 
to study autocrine/paracrine regulatory loops of human trophoblast subpopulations-TNF-alpha stimulates MMP15 expression. BMC Dev Biol 2007, 7:137

30. Palmeira CM, Rolo AP, Berthiaume J, Bjork JA, Wallace KB: Hyperglycemia decreases mitochondrial function: the regulatory role of mitochondrial biogenesis. Toxicol Appl Pharmacol 2007, 225:214220

31. Gao Q, Gao YM: Hyperglycemic condition disturbs the proliferation and cell death of neural progenitors in mouse embryonic spinal cord. Int J Dev Neurosci 2007, 25:349-357

32. Rajesh M, Mukhopadhyay P, Batkai S, Mukhopadhyay B, Patel V, Hasko G, Szabo C, Mabley JG, Liaudet L, Pacher P: Xanthine oxidase inhibitor allopurinol attenuates the development of diabetic cardiomyopathy. J Cell Mol Med 2009, 13:2330-2341

33. Henderson JR, Swalwell H, Boulton S, Manning P, McNeil CJ, BirchMachin MA: Direct, real-time monitoring of superoxide generation in isolated mitochondria. Free Radic Res 2009, 43:796-802

34. Hiden U, Desoye G: The human placenta in diabetes. A Practical Manual of Diabetes in Pregnancy. Edited by McCance DR, Maresh M, Sacks DA. Oxford UK, Wiley-Blackwell 2010, pp. 26-33

35. King GL, Loeken MR: Hyperglycemia-induced oxidative stress in diabetic complications. Histochem Cell Biol 2004, 122:333-338

36. Favaro E, Miceli I, Bussolati B, Schmitt-Ney M, Cavallo Perin P, Camussi G, Zanone MM: Hyperglycemia induces apoptosis of human pancreatic islet endothelial cells: effects of pravastatin on the Akt survival pathway. Am J Pathol 2008, 173:442-450

37. Kobayashi $Y$, Naruse K, Hamada Y, Nakashima E, Kato K, Akiyama N, Kamiya H, Watarai A, Nakae M, Oiso Y, Nakamura J: Human proinsulin C-peptide prevents proliferation of rat aortic smooth muscle cells cultured in high-glucose conditions. Diabetologia 2005, 48: 2396-2401

38. Di Paolo S, Gesualdo L, Ranieri E, Grandaliano G, Schena FP: High glucose concentration induces the overexpression of transforming growth factor-beta through the activation of a platelet-derived growth factor loop in human mesangial cells. Am J Pathol 1996, 149:20952106

39. Huang JS, Chuang LY, Guh JY, Huang YJ, Hsu MS: Antioxidants attenuate high glucose-induced hypertrophic growth in renal tubular epithelial cells. Am J Physiol Renal Physiol 2007, 293:F1072-F1082

40. Cindrova-Davies T, Spasic-Boskovic O, Jauniaux E, Charnock-Jones DS, Burton GJ: Nuclear factor-kappa B, p38, and stress-activated protein kinase mitogen-activated protein kinase signaling pathways regulate proinflammatory cytokines and apoptosis in human placental explants in response to oxidative stress: effects of antioxidant vitamins. Am J Pathol 2007, 170:1511-1520
41. Innat MA, Thorpe JE, Kamat CD, Szabo C, Green DE, Warnke LA, Lacza Z, Cselenyak A, Ross K, Shakir S, Piconi L, Kaltreider RC, Ceriello A: Reactive oxygen species mediate a cellular 'memory' of high glucose stress signaling. Diabetologia 2007, 50:1523-1531

42. Forbes JM, Coughlan MT, Cooper ME: Oxidative stress as a major culprit in kidney disease in diabetes. Diabetes 2008, 57:1446-1454

43. Weidig P, McMaster D, Bayraktutan U: High glucose mediates prooxidant and antioxidant enzyme activities in coronary endothelial cells. Diabetes Obes Metab 2004, 6:432-441

44. Matsunami $T$, Sato $Y$, Sato $T$, Ariga $S$, Shimomura $T$, Yukawa $M$ : Oxidative stress and gene expression of antioxidant enzymes in the streptozotocin-induced diabetic rats under hyperbaric oxygen exposure. Int J Clin Exp Pathol 2009, 3:177-188

45. Jones CJ, Weiss U, Siman CM, Desoye G: Mitochondria from human trophoblast and embryonic liver cells are resistant to hyperglycaemia-associated high-amplitude swelling. Diabetologia 2001, 44:389391

46. Sun J, Xu Y, Sun S, Sun $Y$, Wang $X$ : Intermittent high glucose enhances cell proliferation and VEGF expression in retinal endothelial cells: the role of mitochondrial reactive oxygen species. Mol Cell Biochem 2010, 343:27-35

47. Peng Y, Kwok KH, Yang PH, Ng SS, Liu J, Wong OG, He ML, Kung HF, Lin MC: Ascorbic acid inhibits ROS production. NF-kappa B activation and prevents ethanol-induced growth retardation and microencephaly. Neuropharmacology 2005, 48:426-434

48. Leloup C, Tourrel-Cuzin C, Magnan C, Karaca M, Castel J, Carneiro L, Colombani AL, Ktorza A, Casteilla L, Penicaud L: Mitochondrial reactive oxygen species are obligatory signals for glucose-induced insulin secretion. Diabetes 2009, 58:673-681

49. Poncin S, Colin IM, Decallonne B, Clinckspooor I, Many MC, Denef JF, Gerard AC: N-acetylcysteine and 15 deoxy-\{delta\}12,14-prostaglandin $\mathrm{J} 2$ exert a protective effect against autoimmune thyroid destruction in vivo but not against interleukin-1 \{alpha\}/interferon \{gamma\}-induced inhibitory effects in thyrocytes in vitro. Am J Pathol 2010, 177:219-228

50. Chen YH, Lin SJ, Lin FY, Wu TC, Tsao CR, Huang PH, Liu PL, Chen $Y L$, Chen JW: High glucose impairs early and late endothelial progenitor cells by modifying nitric oxide-related but not oxidative stressmediated mechanisms. Diabetes 2007, 56:1559-1568

51. Peiro C, Lafuente N, Matesanz N, Cercas E, Llergo JL, Vallejo S, Rodriguez-Manas L, Sanchez-Ferrer CF: High glucose induces cell death of cultured human aortic smooth muscle cells through the formation of hydrogen peroxide. Br J Pharmacol 2001, 133:967-974 